\title{
Differing Relations to Early Atherosclerosis between Vitamin C from Supplements vs. Food in the Los Angeles Atherosclerosis Study: A Prospec- tive Cohort Study
}

\author{
Megha Agarwal $^{1}$, Puja K. Mehta ${ }^{1}$, James H. Dwyer ${ }^{\wedge}$, Kathleen M. Dwyer $^{2}$, Anne M. Shircore ${ }^{2}$, \\ Cheryl K. Nordstrom ${ }^{3}$, Ping Sun ${ }^{2}$, Maura Paul-Labrador ${ }^{2 \wedge}$, Yuching Yang ${ }^{1}$ and C. Noel Bairey \\ Merz $^{1, *}$
}

\author{
${ }^{1}$ Women's Heart Center, Cedars-Sinai Heart Institute, Cedars-Sinai Medical Center, Los Angeles, CA, USA \\ ${ }^{2}$ Keck School of Medicine of the University of Southern California, Los Angeles, CA, USA \\ ${ }^{3}$ Center for Health Research, Wayne State University, Detroit, MI, USA
}

${ }^{\wedge}$ Deceased This work was supported by grants from the NHLBI (National Heart, Lung, and Blood Institute, USA; grants R01 HL49910 and R01 073108-01), TRDRP (Tobacco-Related Disease Research Program, USA; grant 7RT-0034) and a GCRC grant MO1-RR00425 from the National Center for Research Resources, and grants from the Gustavus and Louis Pfeiffer Research Foundation, Denville, New Jersey, the Women's Guild of Cedars-Sinai Medical Center, Los Angeles, California, the Edythe L. Broad Women's Heart Research Fellowship, Cedars-Sinai Medical Center, Los Angeles, California, and the Barbra Streisand Women's Cardiovascular Research and Education Program, CedarsSinai Medical Center, Los Angeles, USA

\begin{abstract}
Objective: To determine the relationship of vitamin c intake from supplements vs food on early atherosclerosis detected by carotid intima media thickness (IMT).

Background: Oxidative stress and endothelial dysfunction play a critical role in the pathogenesis of atherosclerosis. Dietary vitamin $\mathrm{C}$ appears to have anti-oxidant properties and beneficial relations to endothelial function, yet vitamin $\mathrm{C}$ taken as a vitamin supplement does not appear to protect from cardiovascular events. The impact of vitamin c intake from supplements vs food on progression of atherosclerosis is unknown.

Methods: We examined 3-year progression of carotid IMT in a randomly sampled cohort of 573 healthy women and men aged 40-60 years. Progression of carotid IMT was determined bilaterally with B-mode ultrasound at 3 examinations (1.5year intervals). Intake of dietary vitamin $\mathrm{C}$ was measured by six, 24-hour recall interviews. Intake of vitamin $\mathrm{C}$ from vitamin supplements was measured by questionnaire in quartiles of supplement intake and no supplement. Vitamin $\mathrm{C}$ wasmeasured in plasma as ascorbic acid.

Results: Carotid IMT progressed 10.0 $\pm 16.5 \mu \mathrm{m} /$ year (mean \pm SD) among all those with follow-up (n=500; 87\%). For those who took vitamin $\mathrm{C}$ supplements, carotid IMT progression increased with dose (p-trend=0.0009). Among persons in the highest quartile (857-5000 mg/day) of vitamin C supplement intake compared to those not consuming any vitamin $\mathrm{C}$ supplements, carotid IMT progression increased three-fold (20.3 \pm 2.6 versus $7.6 \pm 1.8 \mu \mathrm{m} /$ year (mean $\pm \mathrm{SD}) ; \mathrm{p}<0.001)$. The adverse association of vitamin C supplement intake with carotid IMT was two-fold greater in the upper tertile of serum cholesterol compared to the lower two tertiles $(p=0.01)$. In contrast to the adverse association of vitamin $C$ supplements, vitamin $\mathrm{C}$ intake from food had a weak protective relationship on carotid IMT progression (reduced progression $-5.0 \pm 1.9$ $\mu \mathrm{m} /$ year; $\mathrm{p}=0.008)$.

Conclusions: Vitamin C supplementation is associated with accelerated early atherosclerosis measured by carotid IMT compared to a protective association with vitamin $\mathrm{C}$ from food. Theadverse association of vitamin $\mathrm{C}$ supplementation may be greater in patients with higher serum cholesterol levels. The current results provide a potential mechanistic understanding for the observed differences between Vitamin C in supplements vs food in prior studies. Given these observations, vitamin $\mathrm{C}$ supplementation does not appear to be currently advisable for prevention or treatment of atherosclerosis.
\end{abstract}

Keywords: Ascorbic acid, vitamin C, atherosclerosis, cardiovascular disease.

*Address correspondence to this author at the Health Women's Heart Center, Preventive Cardiac Center, Medicine Cedars-Sinai Heart Institute 444 S San Vicente Blvd, Suite 600, Los Angeles, CA90048, USA;

Tel: 310-423-9680; Fax: 310-423-9681; E-mail: merz@cshs.org

\section{INTRODUCTION}

Vitamin C (ascorbic acid) is a water-soluble vitamin that must be consumed from external sources (primarily fruits and vegetables) because humans cannot synthesize it 
endogenously. In addition to being an anti-oxidant, vitamin $\mathrm{C}$ improves endothelial-dependent vascular function, reduces monocyte adhesion to endothelium, reduces vascular smooth muscle cell apoptosis, and impacts oxidative modification of low-density lipoprotein [1]. However, while diets high in fruits and vegetables are associated with reduced cardiovascular disease (CVD) risk [2-5], anti-oxidant vitamin supplements, including vitamin $\mathrm{C}$, have failed to reduce $\mathrm{CVD}$ events in randomized trials [6,7]. Additional evidence suggests there may be a differential impact on CVD between vitamin intake from supplements vs food [8-10]; however mechanistic pathways are not understood.

Previous studies have shown that carotid artery intimal medial thickness (IMT), measured by B-mode ultrasound, is a measure of pre-clinical atherosclerosis, and is a correlate of angiographically determined coronary atherosclerosis [11]. Progression of IMT is associated with conventional atherosclerotic risk factors [12] and CV events [12,13]. We evaluated the relations between intake of vitamin $\mathrm{C}$ from supplements vs. food with progression of carotid artery IMT.

\section{METHODS}

\section{Study Population}

The Los Angeles Atherosclerosis Study (LAAS), a prospective cohort study of employees with uniform health insurance from a large utility company, has been described previously $[14,15]$. Briefly, women aged $45-60$, and men aged 40-60 years at entry were randomly sampled from strata (5-year age, Hispanic/other, current smoker/other). All study subjects were recruited from the same company, from 4 different job categories: union, management, administrative, and other. Employees with diagnosed CVD or current treatment for cancer were excluded. Participation rate was $85 \%$, resulting in a cohort of 573 participants in the baseline examination (1995-1996). Two follow-up examinations were conducted at 1.5 and 3 years from baseline. The Institutional Review Boards at Keck School of Medicine of the University of Southern California, and Cedars-Sinai Medical Center approved the study, and all subjects gave written informed consent prior to participation.

\section{Vitamin Intake}

During baseline visit, dietary vitamin $\mathrm{C}$ intake was measured as the mean of up to six 24 hour (hr) recalls using the Minnesota Nutrition Data System (NDS); three measurements (two weekdays and one weekend or holiday) were taken at baseline, and three at 1.5 year follow-up [16]. Intake of vitamin supplements was measured at baseline and at 1.5 year follow-up with a nurse-assisted questionnaire. Questions concerning frequency and mode of supplemental vitamin C intake were included. Questions asked whether participants were taking vitamin $\mathrm{C}$ and multivitamins. Dosage per tablet (for specific supplements, but not for multivitamins), number of tablets per week, and duration of use were also recorded. Quartiles of multi-vitamin intake were 12, 2.5-3.5, 4.5-6, and 7-25 tablets per week. Quintiles of Vitamin C from food were 17.9-54.1, 54.6-77.6, 77.8-104.6, 104.9-145.8, and 146.1-395.3 mg/day.

\section{Measurement of Plasma Ascorbic Acid}

Plasma ascorbic acid (reduced form, AA) was determined by the method of Kutnink et al. [17]. To prevent oxidation during sample storage, an equal volume of $5 \%$ or $10 \%$ meta-phosphoric acid was added to ethylenediaminetetraacetic acid- plasma(EDTA) [18], and samples were stored at -70 ${ }^{\circ} \mathrm{C}$. The average storage time of samples before analysis averaged 1.2 years. Isoascorbic acid was used as an internal standard to compensate for losses of AA during sample processing. Assays were performed by a laboratory participating in the NCI (National Cancer Institute)/NIST (National Institute of Standards and Technology) Ascorbic Acid Quality Assurance Program ( $\mathrm{CV}=6.9 \%$ from daily plasma pools). No decline in concentration with duration of storage was observed. Given the potentially strong disease effect of atherosclerosis on plasma AA levels [19] and the availability of plasma antioxidant levels only at baseline, plasma levels were used only for validation of baseline intake measures.

\section{Measurement of Carotid IMT}

The LAAS protocol for high resolution B-mode ultrasonographic measurement of IMT in the common carotid artery was used as previously described [15]. Briefly, IMT was measured bilaterally in two body positions (lateral and supine) using an ATL scanner (model UM4+, 7.5 MHz linear transducer). Average thickness over a $1 \mathrm{~cm}$ segment of the distal wall $25 \mathrm{~mm}$ proximal to the bulb was measured using automated edge-tracking software. A reproducibility study yielded a standard deviation of $22 \mu \mathrm{m}$ for differences between repeated scans by different sonographers $(\mathrm{CV}=$ $2.8 \%)[14]$.

\section{Other Measurements}

Examinations were conducted in the morning (after an overnight fast) in a mobile unit driven to the worksite. Ethnicity, alcohol intake, cigarette habit, physical activity, medication use and medical history were collected with an interviewer-assisted questionnaire. The survey detailed the patients' smoking habits including duration and amount of cigarettes and cigars smoked as well as an estimation of second hand smoke exposure. Alcohol intake was quantified by glasses, cans, bottles, and/or shots of wine (10.8 gram/glass), beer (13.2 gram/can), and/or hard liquor (15.1 gram/shot) consumed. Physical activity was assessed by days per week that patients exercise. Blood pressure and body mass index $\left(\mathrm{kg} / \mathrm{m}^{2}\right)$ were measured by a research nurse with a standardized protocol [20].

\section{STATISTICAL ANALYSIS}

Statistical analyses were performed using the maximum likelihood SAS procedure for mixed models (repeated measures with unconstrained covariance structure) [21]. Change in carotid IMT from baseline ( $\mu \mathrm{m} / \mathrm{year}$ ) was regressed on quintiles of dietary intake and five groups of supplement intake (non-users and quartiles among users). Tests of linear trend were performed by placing the constraint $\beta^{\prime} \mathrm{L}=0$, where $\beta$ is a vector of coefficients for quintiles and $L^{\prime}=(-1-0.50$ 0.51 ). For purposes of graphic depiction and a posteriori 
inspection for non-linear dose-response patterns, least squares means and standard errors were also estimated.

Three models were estimated. Model 1 included age in years, sex, sex by age interaction, logarithm of total energy intake, two categorical variables for supplement intake (vitamin $\mathrm{C}$ and low-dose multi-vitamins), categorical variables for dietary intake (vitamin $\mathrm{C}$ from food), and two continuous variables (tablets per week) for stress and therapeutic multiple vitamins. Model 2 added the covariates of smoking habit (current, former smoker), ethnicity (Hispanic, Black, and Asian, non-Hispanic white and other), alcohol intake (quintiles), physical activity (quintiles of number of strenuous activity sessions per week), use of anti-hypertensive medication, use of lipid lowering medication, diagnosis of diabetes, and number of cold/flu episodes in the previous year. Model 3 added the covariates of serum cholesterol level, systolic blood pressure and body mass index $\left(\mathrm{kg} / \mathrm{m}^{2}\right)$ as continuous variables. If dietary and supplement intake mediate their effects via pathways that include an impact on the biological variables in Model 3, then Model 3 may underestimate effects.

\section{RESULTS}

Characteristics of the study subjects by supplement intake of vitamin $\mathrm{C}$, low-dose multi-vitamins, and vitamin $\mathrm{C}$ intake from foodare shown in Tables $\mathbf{1}$ and 2.Vitamin $\mathrm{C}$ intake from food was strongly associated with male sex (Table 2), possibly due to increased food intake among men. Nonsmokers had a higher intake of vitamin $\mathrm{C}$ from food than smokers $(p=0.006)$.Intake of low-dose multi-vitamins was moderately positively correlated with intake of vitamin $\mathrm{C}$ supplements, but did not reach statistical significance $(\mathrm{p}=0.21)$. Follow-up was conducted among $87 \%(\mathrm{n}=500)$ of the cohort (480 persons at 1.5 -years and 447 at 3 -years). No significant differences in demographic characteristics $(\mathrm{p}>0.10)$ between those who completed the study and subjects that were lost to follow-up.

Plasma AA at baseline increased with both dietary and supplemental vitamin $C$ intake. Among persons with no intake of supplement containing vitamin C, plasma AA increased monotonically from) $26.3 \pm 21$ to $39.1 \pm 19$ (mean \pm SD) $\mu \mathrm{mol} / \mathrm{L}$ across quintiles of vitamin $\mathrm{C}$ from food (P-trend $<0.001)$. After adjustment for intake of vitamin $\mathrm{C}$ from food, plasma AA among those who took vitamin $\mathrm{C}$ supplements was further elevated by $3.5 \pm 20,14.8 \pm 16$, $10.2 \pm 16$, and $19.7 \pm 15 \mu \mathrm{mol} / \mathrm{L}$ across quartiles of vitamin $\mathrm{C}$ intake from vitamin $\mathrm{C}$ supplements (P-trend $<0.001)$.

\section{IMT Progression and Internal Validity}

Mean IMT at baseline was $665.5 \mu \mathrm{m}(\mathrm{SD}=98.3)$. Carotid IMT progressed 10.0 $\pm 16.5 \mu \mathrm{m} /$ year (mean \pm SD) among all those with follow-up $(n=500 ; 87 \%)$ over three years. In a multivariate model including age and sex, progression rate for IMT was significantly increased with current cigarette smoking $(\mathrm{p}=0.01)$, serum cholesterol $(\mathrm{p}=0.03)$, and systolic blood pressure $(\mathrm{p}=0.01)$.

\section{IMT and Vitamin C Supplement Intake}

Progression rate of IMT among subjects reporting no intake of vitamin $\mathrm{C}$ supplements and those who did report use of supplements are presented in (Table 3 and Fig. 1) by supplement dose quartiles. Among persons in the highest quartile (857-5000 mg/day) of vitamin C supplement intake compared to those not consuming any vitamin $\mathrm{C}$ supplements, carotid IMT progression increased three-fold $(20.3 \pm 2.6$ versus $7.6 \pm 1.8 \mu \mathrm{m} /$ year $($ mean \pm SD); $p<0.001)$. As intake of vitamin $\mathrm{C}$ supplements increased, IMT progression rate increased ( $p$-trend $=0.0009$, Model 1). Adjustment for potential confounders in Models 2 and 3 did not alter this pattern (Table 3 ).

\section{Carotid IMT and Multi-vitamin Intake}

Intake of low-dose multi-vitamins was not significantly related to carotid IMT progression ( $\mathrm{p}$-trend=0.28, Table 3 ). However, there was significantly less carotid IMT progression among participants reporting weekly intake of at least one tablet (first quartile), relative to participants who reported no use of low-dose multi-vitamins ( $\mathrm{p}=0.07$, Model 1 ). Adjustment for potential confounders reduced this difference, but it was not statistically significant $(\mathrm{p}=0.09$ in Model 3 ). The second quartile of multi-vitamin supplement intake (about 3 tablets per week) was associated with reduced progression in all three models.

\section{Carotid IMT and Vitamin C Intake from Food Only}

The relations between vitamin $\mathrm{C}$ intake from food and IMT progression are presented in Table 4. There were no significant linear trends across dietary intake quintiles; however, carotid IMT progression was reduced in the highest quintile of dietary vitamin $\mathrm{C}$ intake relative to the other four quintiles $(-5.0 \pm 1.9 \mu \mathrm{m} /$ year; $\mathrm{p}=0.008$ in Model 1$)$. This difference was reduced by adjustment $(-3.6 \pm 1.8 \mu \mathrm{m} /$ year; $\mathrm{p}=0.04$ in Model 3), reflecting the correlation between smoking and vitamin $\mathrm{C}$ intake from food. Exclusion of subjects being treated for hypertension, dyslipidemia, and diabetes increased this difference $(-4.6 \pm 1.9 \mu \mathrm{m} /$ year; $p=0.01$ in Model 3).

\section{Interactions}

Current smoking did not significantly modify the association of vitamin $\mathrm{C}$ supplements $(\mathrm{p}=0.12)$ with IMT progression. The adverse association of vitamin $\mathrm{C}$ supplement intake in the upper tertile of serum cholesterol level $(\geq 6.0$ $\mathrm{mmol} / \mathrm{L}$ ) was 2 -fold greater than in the lower two tertiles $(p=0.01)$. A marginal interaction was also observed between vitamin $\mathrm{C}$ supplement intake and use of anti-hypertensive medication $(p=0.06)$, where the adverse association of vitamin C supplements on carotid IMT progression was doubled among anti-hypertensive medication users. Inclusion of both these interactions into the model yielded stronger effect modification $(p=0.0002$ for serum cholesterol and $p=0.005$ for anti-hypertensive medication).

\section{DISCUSSION}

To our knowledge, this is the first study to report greater progression of carotid IMT in those who took vitamin C supplements, compared to a relatively less progression of carotid IMT among those with a greater vitamin $\mathrm{C}$ intake from food. The adverse association of vitamin $\mathrm{C}$ supplement in- 
Table 1. Baseline Characteristics of Participants by Vitamin C Supplement intake and Low-dose Multi-Vitamin Supplement Intake. LAAS, 1994-1999 ( $\mathrm{N}=500)$

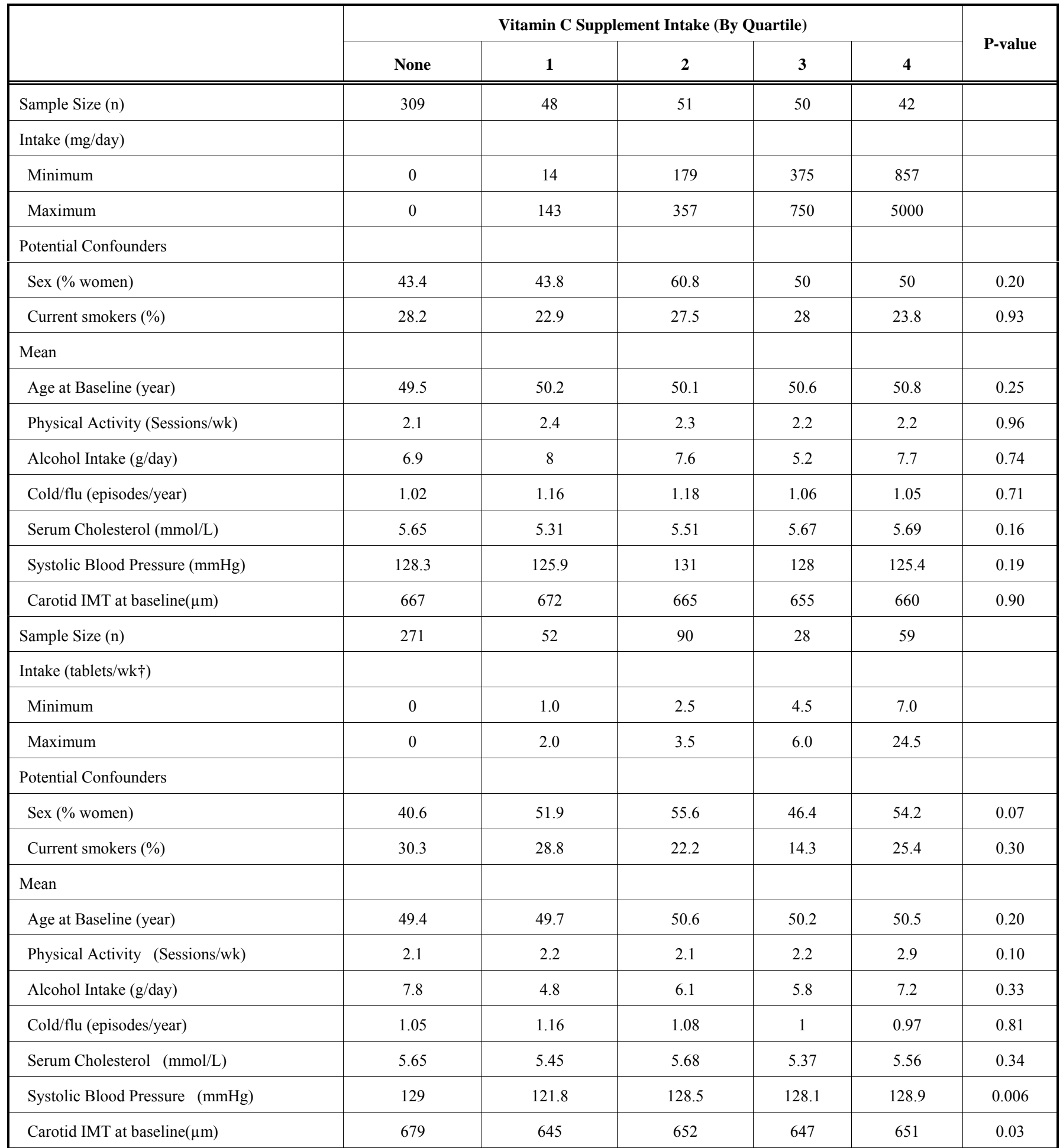

$\uparrow$ Quartiles of multiple vitamin intake were 1-2, 2.5-3.5, 4.5-6 and 7-25 tablets per week. Uneven numbers arise from averaging reports at two examinations.

take was most evident in those subjects with elevated serum cholesterol level and among those with hypertension. The current results provide a potential mechanistic understanding for the differential effects of vitamin $\mathrm{C}$ in supplements compared to food.
The finding that vitamin $\mathrm{C}$ supplements had an adverse association with atherosclerosis, while vitamin $\mathrm{C}$ intake from food may be protective is consistent with studies that point to a differential impact between vitamin intake from food and vitamin intake from supplements [8-10]. For example, dietary vitamin $\mathrm{E}$ intake has been associated with beneficial 
Table 2. Characteristics of the Los Angeles Atherosclerosis Study (LAAS) Subjects by Quintile of Vitamin C Intake from Food. Data are from LAAS, 1994-1999 ( $\mathrm{N}=500)$

\begin{tabular}{|c|c|c|c|c|c|c|}
\hline & \multicolumn{5}{|c|}{ Vitamin C Intake from food (By Quintile) } & P-value \\
\hline \multicolumn{7}{|l|}{ Intake (mg/day) } \\
\hline Minimum & 17.9 & 54.6 & 77.8 & 104.9 & 146.1 & \\
\hline \multicolumn{7}{|l|}{ Potential Confounders } \\
\hline Sex (\% women) & 66.7 & 41.6 & 48.1 & 45.0 & 30.9 & 0.0001 \\
\hline Current smokers (\%) & 40.6 & 28.7 & 26.4 & 23.0 & 17.5 & 0.006 \\
\hline \multicolumn{7}{|l|}{ Mean } \\
\hline Alcohol Intake (g/day) & 7.6 & 7.6 & 6.2 & 6.0 & 7.7 & 0.67 \\
\hline Cold/flu (episodes/year) & 1.06 & 1.12 & 1.01 & 0.98 & 1.13 & 0.68 \\
\hline Serum Cholesterol $(\mathrm{mmol} / \mathrm{L})$ & 5.62 & 5.75 & 5.52 & 5.53 & 5.63 & 0.43 \\
\hline Systolic Blood Pressure (mmHg) & 128.5 & 128.8 & 128 & 129.2 & 125.8 & 0.36 \\
\hline Carotid IMT at baseline $(\mu \mathrm{m})$ & 659 & 668 & 670 & 672 & 657 & 0.75 \\
\hline
\end{tabular}

effects $[22,23]$ and, at doses of 50 to $537 \mathrm{mg} /$ day, no effect on CVD risk was seen [24-27], but a meta-analyses on high dose vitamin E supplementation has suggested harm [28]. In a meta-analysis of 14 cohort studies on vitamin $\mathrm{C}$ by $\mathrm{Ye}$ et al. showed that dietary intake of vitamin C (but not supplemental vitamin $\mathrm{C}$ ) had an inverse association with coronary heart disease risk [4]. Several explanations for this difference between supplements vs. intake from food for vitamins exist. Studies have reported equal bioavailability of ascorbic acid from food vs. supplemental ascorbic acid from vitamins [2931 , and there is no distinction between the chemical structures of vitamin $\mathrm{C}$ from these two sources, but vitamin $\mathrm{C}$ from fruits and vegetables may be accompanied by interacting components and cofactors, such as carotenoids and flavonoids, that have beneficial effects compared to vitamin $\mathrm{C}$ supplements $[32,33]$. This theory is supported by epidemiological studies that demonstrate low $\beta$-carotene concentrations increase the risk of cardiovascular disease mortality and that increased flavonoid intake from food is associated with decreased risk of heart disease and mortality [34-37]. These studies are mostly dietary observational trials therefore isolating the individual impact of each antioxidant is not possible. Furthermore, large prospective clinical trials evaluating carotenoids, flavonoids, and the other 8000 phenol derivatives that are found in fruits and vegetables that have antioxidant properties [32], independently are lacking.

The results of our study are consistent with several cardiovascular primary and secondary prevention studies that failed to show benefit with vitamin C supplementation, when used alone or as part of an anti-oxidant cocktail [6, 38-41].
Two large-scale randomized trials tested the individual effect of vitamin C supplements on primary CVD prevention and found no reduction in the incidence of major cardiovascular events $[6,7]$. The Physicans' Health Study II, a randomized controlled trial, reported a lack of effect of vitamin C supplement on major CVD events in 14,641 US male physicians over an 8 year follow-up period [7]. Similarly, no CVD benefits of vitamin $\mathrm{C}$ supplement were observed in the Women's Antioxidant Cardiovascular Study in 8,171 highrisk women [6]. More recently, a large-scale, placebocontrolled, randomized trial reported a possible adverse interaction between vitamin $\mathrm{C}$ and the combination therapy with folic acid, vitamin $\mathrm{B}_{6}$, and vitamin $\mathrm{B}_{12}$ on the CVD events in a high-risk population of women over 7.3 years of follow-up [42]. The risk of CVD events for folic acid was higher among those receiving active vitamin $\mathrm{C}$ than those receiving placebo ( $p$-value for interaction $=0.03$ ) [42]. Of note, vitamin supplementation $(C, D, E)$ in general has not been shown to consistently reduce the risk of diseases, such as cancer, where theoretically the role of anti-oxidants vitamins should be beneficial [43-46].

When vitamin $\mathrm{C}$ supplements are administered in conjunction with other anti-oxidant supplements, effects on early atherosclerosis progression are inconsistent [23, 47, 48]. One study reported that combined vitamin $C$ and $E$ supplementscan slow down the progression of IMT in men [23], however a larger trial conducted on 1162 apparently healthy subjects found that carotid IMT was not different between participants who received a combination of vitamin $\mathrm{C}, \mathrm{E}$, beta-carotene, and selenium versus placebo [47]. Waters et 
Table 3. Progression of Carotid Intima-Media Thickness (IMT, $\mu \mathrm{m} / \mathrm{year}$ ) by Quartile of Vitamin C and low-dose Multi-vitamin Supplement Intake. Data are from the Los Angeles Atherosclerosis Study (LAAS), 1994-1999 (N=500)

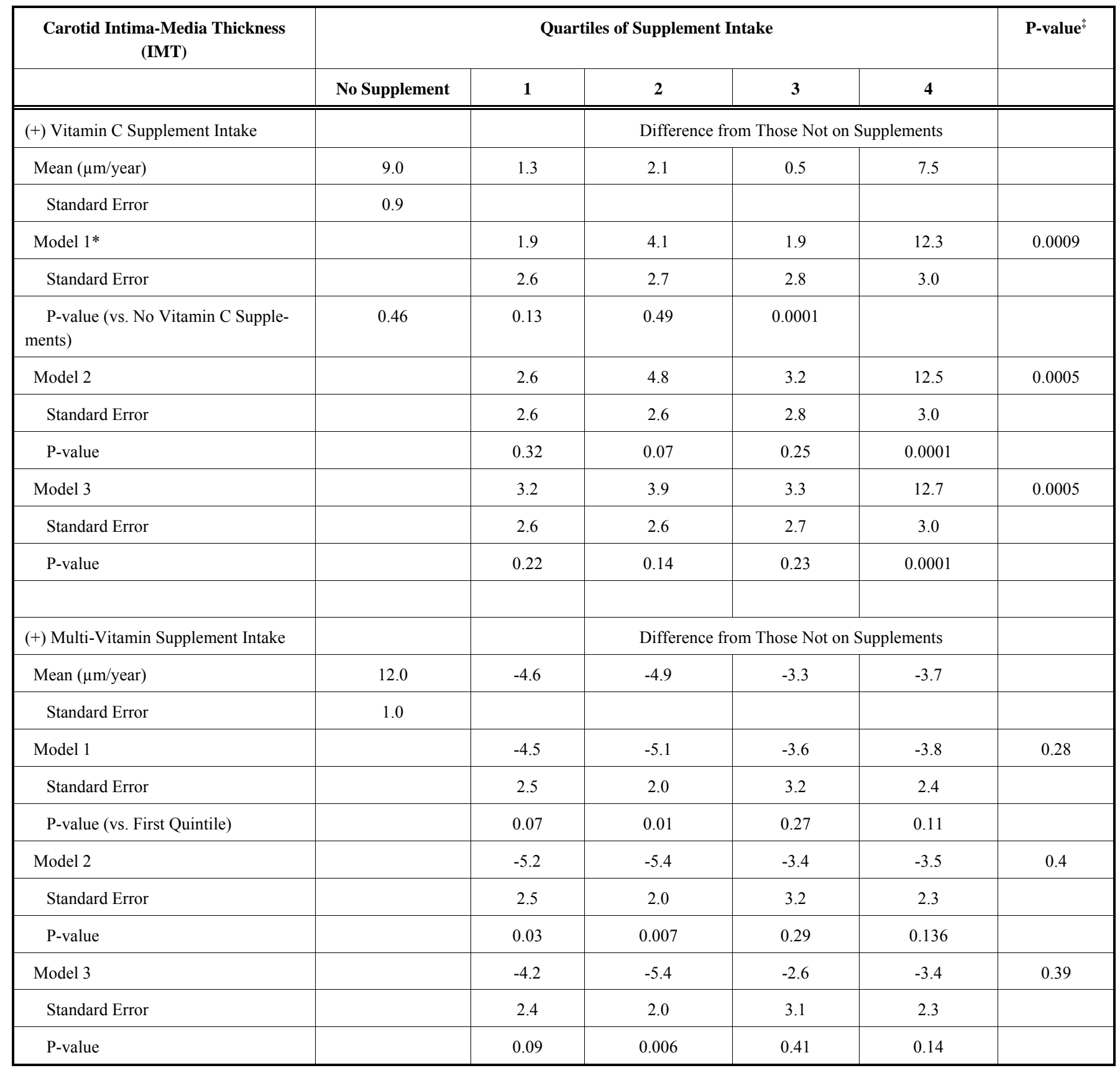

* Model 1 was adjusted for age at baseline, sex, other supplements, intake of vitamin $\mathrm{C}$ and $\mathrm{E}$ from food and total energy intake. Model 2 added adjustment for ethnicity (non-Hispanic white, Hispanic, Black, Asian, other), alcohol intake (quintiles), vigorous physical activity (quintiles), treatment with antihypertensive medication, treatment with cholesterol lowering medication, diabetes (Type I or II), and frequency of colds or flu. Model 3 added adjustment for serum cholesterol, systolic blood pressure and body mass index.

$\ddagger$ Rate of IMT progression was reduced among multiple vitamin supplementers (combining across dose groups) relative to non-supplementers ( $\leq \leq 0.01$ in all three models).

al. [48] confirmedthat a high-dose antioxidant vitamin supplement of $800 \mathrm{IU}$ of vitamin $\mathrm{E}$ and $1000 \mathrm{mg}$ of vitamin $\mathrm{C}$ per day compared to placebo in post-menopausal women provided no reduction in CVD events; however, they showed an increase in all-cause mortality in post-menopausal women with anti-oxidant vitamin consumption compared to women with placebo (HR, 2.8; 95\% CI 1.1-7.2). Notably, the dose of vitamin $\mathrm{C}$ in this study associated with an increase in all- cause mortality was 2-fold higher than other studies that did not find similar results. These observations mirror our finding of greater IMT progression in subjects with increased supplementary vitamin $\mathrm{C}$ intake.

Additional data suggest important adverse interactions between vitamin supplements and prescribed medications. An angiographic trial found that an antioxidant cocktail (in- 
Table 4. Progression of Common Carotid Intima-media Thickness (IMT, $\mu \mathrm{m} / \mathrm{year}$ ) by Quintile of Intake of Vitamin C from the Diet. Data are from the Los Angeles Atherosclerosis Study, 1994-1999 (n=500)

\begin{tabular}{|c|c|c|c|c|c|c|}
\hline \multirow{2}{*}{$\begin{array}{c}\text { Carotid Intima-Media Thickness (IMT) } \\
\text { (+) Dietary Vitamin C Intake }\end{array}$} & \multicolumn{5}{|c|}{ Quintiles of Vitamin C Intake from Food } & P-value $\dagger$ \\
\hline & 1 & \multicolumn{4}{|c|}{ Difference from First Quintile } & \\
\hline Mean $(\mu \mathrm{m} /$ year $)$ & 8.5 & 2.2 & 3.7 & 2.4 & -1.1 & \\
\hline Standard Error & 1.7 & & & & & \\
\hline Standard Error & & 2.3 & 2.3 & 2.4 & 2.5 & \\
\hline P-value (vs. First Quintile) & 0.76 & 0.28 & 0.93 & 0.10 & & \\
\hline Model 2 & & 1.1 & 4.0 & 1.4 & -2.1 & 0.5 \\
\hline Standard Error & & 2.3 & 2.3 & 2.4 & 2.5 & \\
\hline Standard Error & & 2.3 & 2.3 & 2.3 & 2.5 & \\
\hline P-value & & 0.6 & 0.04 & 0.5 & 0.47 & \\
\hline
\end{tabular}

* For definitions of Models 1, 2 and 3, see notes to Table 2.

$\dagger$ Rate of IMT progression was reduced in the top quintile of vitamin $\mathrm{C}$ intake relative to the other four quintiles ( $\mathrm{p}=0.008,0.05$ and 0.04 in Models 1,2 and 3 , respectively).

(A)

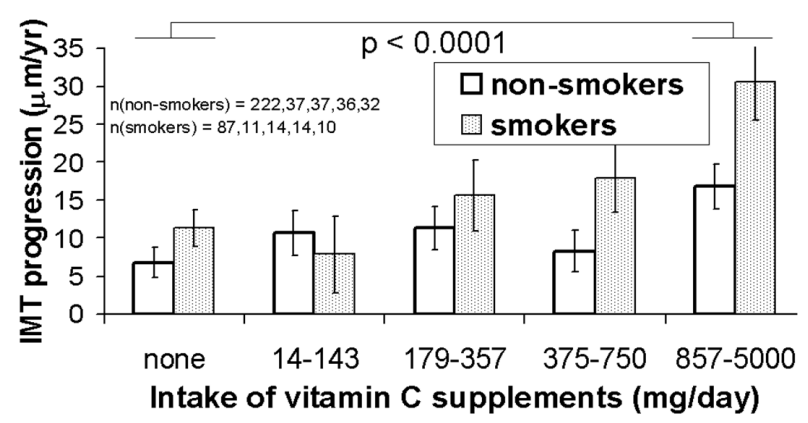

(B)

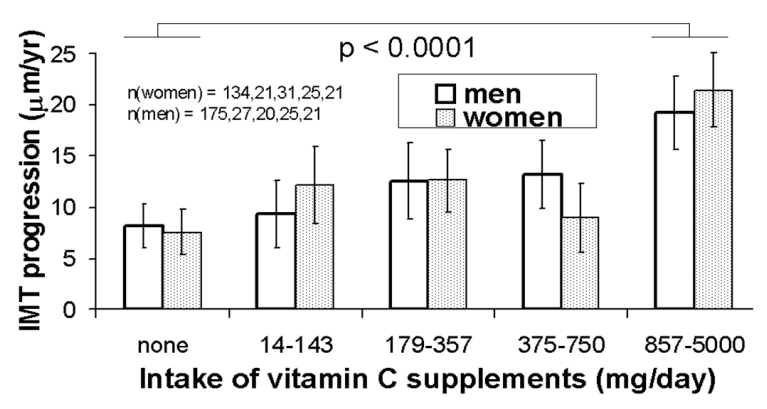

Fig. (1). IMT progression rate by quartiles of intake of vitamin C supplements and sex (A) and baseline smoking status (B). Means are adjusted for the covariates in Model 3 (intake of multiple vitamin supplements; intake of vitamins from food; age, ethnicity and cardiovascular risk factors). Error bars are standard errors. The $\mathrm{p}$ value is for trend test in progression rate of IMT across vitamin $\mathrm{C}$ supplement dose quartiles.

cluding $500 \mathrm{mg}$ vitamin $\mathrm{C}$ and $400 \mathrm{IU}$ vitamin $\mathrm{E}$ ) reduced the beneficial effect of statins and niacin on coronary atherosclerosis [49]. It was postulated that this effect may have been due to an adverse effect of the vitamin supplement on serum high-density lipoprotein (HDL) [50]. We observed an adverse association of vitamin $\mathrm{C}$ supplementation with carotid IMT progression among subjects with relatively higher serum cholesterol levels ( $\mathrm{p}$-value for interaction $=0.01$ ), however, because only a few of our subjects were taking cholesterol lowering medications such as fibrates, niacin, and lowpotency statins, we were unable to evaluate this interaction. Our results suggest that possible adverse association of vitamin C supplements may be even larger in coronary patients with elevated cholesterol similar to the results by Cheung et al. [50].
Strengths of our study include longitudinal measurements of early atherosclerosis concurrent with rigorously measured supplement and dietary vitamin $\mathrm{C}$ intake. The focus on early atherosclerosis avoids changes of intake in response to diagnosis, and concurrent measurement reduces the dilution of associations that occurs when baseline measurements of time-varying characteristics are related to future events. Confidence in the validity of measurements was enhanced by IMT reproducibility [15] and validation of self-reported dietary intake by plasma levels of AA. In addition, the high prevalence of supplement use and a wide range of intake levels in this Southern California cohort increased statistical power. The high participation rate after stratified random sampling from a population with uniform health insurance avoids numerous potential confounding factors. Confidence 
in the reliability of the observed associations between supplement intake and carotid IMT progression is supported by the consistency of findings across sexes and smoking status.

\section{STUDY LIMITATIONS}

Due to the observational design of our study, there are inherent limitations. Unmeasured factors may be confounded with measured intake of supplements and food, or residual confounding by poorly measured risk factors may dilute covariate adjustments [21]. For example, the reduction in carotid IMT progression observed in the highest quintile of dietary vitamin $\mathrm{C}$ intake was attenuated by adjustment for smoking is suggestive of residual confounding. Previous studies have shown that smokers tend to have lower levels of Vitamin C, and therefore the recommended dietary allowance of Vitamin C for smokers is higher [51]. There was no clear pattern of association between supplement intake and lifestyle or biological CV risk factors, which argues against confounding by a general "healthy lifestyle" factor. In addition, data regarding supplement use and dietary patterns were obtained through memory recall which may be error prone.The present study was only an anatomic assessment of IMT; therefore, we cannot draw conclusions about plaque morphology or metabolism, which impacts stability of the plaque and causes $\mathrm{CV}$ events.

\section{CONCLUSIONS}

In summary, our findings suggest that intake of vitamin $\mathrm{C}$ supplements has an adverse association with early atherosclerosis while dietary vitamin $\mathrm{C}$ from food has a protective association. Our results further suggest that the adverse association of vitamin $\mathrm{C}$ supplements may be relatively greater among subjects with elevated cholesterol levels. The current results provide a potential mechanistic understanding for the observed differences between Vitamin C in supplements vs food in prior studies. Based on our observations, vitamin $\mathrm{C}$ supplementation does not appear to be currently advisable for the prevention or treatment of CVD.

\section{ACKNOWLEDGEMENT}

None declared.

\section{CONFLICT OF INTEREST}

The authors confirm that this article content has no conflicts of interest.

\section{REFERENCES}

[1] Aguirre R, May JM. Inflammation in the vascular bed: importance of vitamin C. Pharmacol Ther 2008; 119: 96-103.

[2] Li Y, Schellhorn HE. New developments and novel therapeutic perspectives for vitamin C. J Nutr 2007; 137: 2171-84.

[3] Willcox BJ, Curb JD, Rodriguez BL. Antioxidants in cardiovascular health and disease: key lessons from epidemiologic studies. Am J Cardiol 2008; 101: 75D-86.

[4] Ye Z, Song H. Antioxidant vitamins intake and the risk of coronary heart disease: meta-analysis of cohort studies. Eur J Cardiovasc Prev Rehabil 2008; 15: 26-34.

[5] Dauchet L, Amouyel P, Hercberg S, Dallongeville J. Fruit and vegetable consumption and risk of coronary heart disease: a metaanalysis of cohort studies. J Nutr 2006; 136: 2588-93.
[6] Cook NR, Albert CM, Gaziano JM, et al. A randomized factorial trial of vitamins $\mathrm{C}$ and $\mathrm{E}$ and beta carotene in the secondary prevention of cardiovascular events in women: results from the Women's Antioxidant Cardiovascular Study. Arch Intern Med 2007; 167: 1610-8

[7] Sesso HD, Buring JE, Christen WG, et al. Vitamins E and C in the prevention of cardiovascular disease in men: the Physicians' Health Study II randomized controlled trial. JAMA 2008; 300: 2123-33.

[8] Lee DH, Folsom AR, Harnack L, Halliwell B, Jacobs DR, Jr. Does supplemental vitamin $\mathrm{C}$ increase cardiovascular disease risk in women with diabetes? Am J Clin Nutr 2004; 80: 1194-200.

[9] Muntwyler J, Hennekens CH, Manson JE, Buring JE, Gaziano JM. Vitamin supplement use in a low-risk population of US male physicians and subsequent cardiovascular mortality. Arch Intern Med 2002; 162: 1472-6.

[10] Osganian SK, Stampfer MJ, Rimm E, et al. Vitamin C and risk of coronary heart disease in women. J Am Coll Cardiol 2003; 42: 24652.

[11] Mack WJ, LaBree L, Liu C, Selzer RH, Hodis HN. Correlations between measures of atherosclerosis change using carotid ultrasonography and coronary angiography. Atherosclerosis 2000; 150: 371-9.

[12] Nagai Y, Metter EJ, Earley CJ, et al. Increased carotid artery intimal-medial thickness in asymptomatic older subjects with exercise-induced myocardial ischemia. Circulation 1998; 98: 15049.

[13] Hodis HN, Mack WJ, LaBree L, et al. The role of carotid arterial intima-media thickness in predicting clinical coronary events. Ann Intern Med 1998; 128: 262-9.

[14] Dwyer JH, Navab M, Dwyer KM, et al. Oxygenated carotenoid lutein and progression of early atherosclerosis: the Los Angeles atherosclerosis study. Circulation 2001; 103: 2922-7.

[15] Dwyer JH, Sun P, Kwong-Fu H, Dwyer KM, Selzer RH. Automated intima-media thickness: the Los Angeles Atherosclerosis Study. Ultrasound Med Biol 1998; 24: 981-7.

[16] Feskanich D, Sielaff BH, Chong K, Buzzard IM. Computerized collection and analysis of dietary intake information. Comput Methods Programs Biomed 1989; 30: 47-57.

[17] Kutnink MA, Hawkes WC, Schaus EE, Omaye ST. An internal standard method for the unattended high-performance liquid chromatographic analysis of ascorbic acid in blood components. Anal Biochem 1987; 166: 424-30.

[18] Margolis SA, Paule RC, Ziegler RG. Ascorbic and dehydroascorbic acids measured in plasma preserved with dithiothreitol or metaphosphoric acid. Clin Chem 1990; 36: 1750-5.

[19] Langlois M, Duprez D, Delanghe J, De Buyzere M, Clement DL. Serum vitamin C concentration is low in peripheral arterial disease and is associated with inflammation and severity of atherosclerosis. Circulation 2001; 103: 1863-8.

[20] Sun P, Dwyer KM, Merz CN, et al. Blood pressure, LDL cholesterol, and intima-media thickness: a test of the "response to injury" hypothesis of atherosclerosis. Arterioscler Thromb Vasc Biol 2000; 20: 2005-10.

[21] Dwyer JH. Statistical Models for the social and behavioral sciences. New York: Oxford University Press 1983.

[22] Rimm EB, Stampfer MJ, Ascherio A, Giovannucci E, Colditz GA, Willett WC. Vitamin E consumption and the risk of coronary heart disease in men. N Engl J Med 1993; 328: 1450-6.

[23] Salonen JT, Nyyssonen K, Salonen R, et al. Antioxidant Supplementation in Atherosclerosis Prevention (ASAP) study: a randomized trial of the effect of vitamins $\mathrm{E}$ and $\mathrm{C}$ on 3-year progression of carotid atherosclerosis. J Intern Med 2000; 248: 377-86.

[24] The effect of vitamin $E$ and beta carotene on the incidence of lung cancer and other cancers in male smokers. The Alpha-Tocopherol, Beta Carotene Cancer Prevention Study Group. N Engl J Med 1994; 330: 1029-35.

[25] Dietary supplementation with n-3 polyunsaturated fatty acids and vitamin E after myocardial infarction: results of the GISSIPrevenzione trial. Gruppo Italiano per lo Studio della Sopravvivenza nell'Infarto miocardico. Lancet 1999; 354: 447-55.

[26] Boaz M, Smetana S, Weinstein T, et al. Secondary prevention with antioxidants of cardiovascular disease in endstage renal disease (SPACE): randomised placebo-controlled trial. Lancet 2000; 356: 1213-8. 
[27] Lonn E, Yusuf S, Dzavik V, et al. Effects of ramipril and vitamin E on atherosclerosis: the study to evaluate carotid ultrasound changes in patients treated with ramipril and vitamin $\mathrm{E}$ (SECURE). Circulation 2001; 103: 919-25.

[28] Miller ER, 3rd, Pastor-Barriuso R, Dalal D, Riemersma RA, Appel LJ, Guallar E. Meta-analysis: high-dosage vitamin E supplementation may increase all-cause mortality. Ann Intern Med 2005; 142: 37-46.

[29] Bates CJ. Bioavailability of vitamin C. Eur J Clin Nutr 1997; 51 (Suppl. 1): S28-33.

[30] Gregory JF, 3rd. Ascorbic acid bioavailability in foods and supplements. Nutr Rev 1993; 51: 301-3.

[31] Mangels AR, Block G, Frey CM, et al. The bioavailability to humans of ascorbic acid from oranges, orange juice and cooked broccoli is similar to that of synthetic ascorbic acid. J Nutr 1993; 123: 1054-61.

[32] Blomhoff R. Dietary antioxidants and cardiovascular disease. Curr Opin Lipidol 2005; 16: 47-54.

[33] Demmig-Adams B, Adams WW $3^{\text {rd }}$. Antioxidants in photosynthesis and human nutrition. Science 2002; 298: 2149-53.

[34] Karppi J, Laukkanen JA, Makikallio TH, Ronkainen K, Kurl S. Low beta-carotene concentrations increase the risk of cardiovascular disease mortality among Finnish men with risk factors. Nutr Metab Cardiovasc Dis 2012 [epub ahead of print].

[35] Hertog MG, Kromhout D, Aravanis C, et al. Flavonoid intake and long-term risk of coronary heart disease and cancer in the seven countries study. Arch Intern Med 1995; 155: 381-6.

[36] Knekt P, Jarvinen R, Reunanen A, Maatela J. Flavonoid intake and coronary mortality in Finland: a cohort study. Br Med J 1996; 312 : 478-81.

[37] Mink PJ, Scrafford CG, Barraj LM, et al. Flavonoid intake and cardiovascular disease mortality: a prospective study in postmenopausal women. Am J Clin Nutr 2007; 85: 895-909.

[38] MRC/BHF Heart Protection Study of antioxidant vitamin supplementation in 20,536 high-risk individuals: a randomised placebo-controlled trial. Lancet 2002; 360: 23-33.

[39] Blot WJ, Li JY, Taylor PR, et al. Nutrition intervention trials in Linxian, China: supplementation with specific vitamin/mineral combinations, cancer incidence, and disease-specific mortality in the general population. J Natl Cancer Inst 1993; 85: 1483-92.
[40] Brown BG, Zhao XQ, Chait A, et al. Simvastatin and niacin, antioxidant vitamins, or the combination for the prevention of coronary disease. N Engl J Med 2001; 345: 1583-92.

[41] Hercberg S, Galan P, Preziosi P, et al. The SU.VI.MAX Study: a randomized, placebo-controlled trial of the health effects of antioxidant vitamins and minerals. Arch Intern Med 2004; 164 : 2335-42.

[42] Albert CM, Cook NR, Gaziano JM, et al. Effect of folic acid and B vitamins on risk of cardiovascular events and total mortality among women at high risk for cardiovascular disease: a randomized trial. JAMA 2008; 299: 2027-36.

[43] Kirsh VA, Hayes RB, Mayne ST, et al. Supplemental and dietary vitamin $\mathrm{E}$, beta-carotene, and vitamin $\mathrm{C}$ intakes and prostate cancer risk. J Natl Cancer Inst 2006; 98: 245-54.

[44] Hutchinson J, Lentjes MA, Greenwood DC, et al. Vitamin C intake from diary recordings and risk of breast cancer in the UK Dietary Cohort Consortium. Eur J Clin Nutr 2012; 66: 561-8.

[45] Lonn E, Bosch J, Yusuf S, et al. Effects of long-term vitamin E supplementation on cardiovascular events and cancer: a randomized controlled trial. JAMA 2005; 293: 1338-47.

[46] Wactawski-Wende J, Kotchen JM, Anderson GL, et al. Calcium plus vitamin D supplementation and the risk of colorectal cancer. $\mathrm{N}$ Engl J Med 2006; 354: 684-96.

[47] Zureik M, Galan P, Bertrais S, et al. Effects of long-term daily lowdose supplementation with antioxidant vitamins and minerals on structure and function of large arteries. Arterioscler Thromb Vasc Biol 2004; 24: 1485-91.

[48] Waters DD, Alderman EL, Hsia J, et al. Effects of hormone replacement therapy and antioxidant vitamin supplements on coronary atherosclerosis in postmenopausal women: a randomized controlled trial. JAMA 2002; 288: 2432-40.

[49] Kuller LH. A time to stop prescribing antioxidant vitamins to prevent and treat heart disease? Arterioscler Thromb Vasc Biol 2001; 21: 1253.

[50] Cheung MC, Zhao XQ, Chait A, Albers JJ, Brown BG. Antioxidant supplements block the response of HDL to simvastatin-niacin therapy in patients with coronary artery disease and low HDL. Arterioscler Thromb Vasc Biol 2001; 21: 1320-6.

[51] Schectman G, Byrd JC, Hoffmann R. Ascorbic acid requirements for smokers: analysis of a population survey. Am J Clin Nutr 1991; 53: $1466-70$.

Received: July 11, 2012

Revised: July 26, 2012

Accepted: August 06, 2012

(C) Agarwal et al.; Licensee Bentham Open.

This is an open access article licensed under the terms of the Creative Commons Attribution Non-Commercial License (http://creativecommons.org/licenses/ by-nc/3.0/) which permits unrestricted, non-commercial use, distribution and reproduction in any medium, provided the work is properly cited. 